\title{
Improvement of the Photoluminescence of Porous Si Powder via Oxidation in Organic Solvents
}

\author{
R. Nishio ${ }^{1}$, K. Matsumoto ${ }^{1 *}$, Y. Mabuchi ${ }^{1}$, K. Kamiya ${ }^{1}$, T. Nomura ${ }^{1}$, S. Kawabata ${ }^{1}$, M. Inada $^{2}$, \\ and $\mathrm{S}$. Suzuki ${ }^{3}$ \\ 1 Toyama Prefectural University, Imizu, Toyama, Japan \\ 2 Kansai University, Suita, Osaka, Japan \\ 3 Nagano National College of Technology, Nagano, Japan \\ * Corresponding author: matsu@pu-toyama.ac.jp
}

\begin{abstract}
We studied the photoluminescence (PL) of porous Si powder via oxidation in distilled water and organic solvents of ethanol, acetone and hexane. Porous Si powder aged in an ethanol solution increased in PL intensity up to 50 times over 4 days. Even though the PL intensity of porous Si aged in acetone and hexane solutions also increased, the increase was smaller than that of seen in the ethanol solution. Porous Si powder oxidized in an ethanol solution shows the best improvement in PL intensity for all the used solvents. However, the PL intensity of porous Si aged in distilled water decreased. The PL intensity of porous Si aged in deaerated ethanol slowly increased indicating that the surface oxidation of porous $\mathrm{Si}$ was caused by the oxygen dissolved in the organic solvents. Oxidation of a porous Si surface strongly depends on the type of organic solvent.
\end{abstract}

Keywords: porous $\mathrm{Si}$, oxidation, photoluminescence, aging in organic solvents

\section{INTRODUCTION}

Since visible and infrared luminescence has been observed in porous $\mathrm{Si}$ via the quantum size effect ${ }^{1}, \mathrm{Si}$ nanoparticles have been studied to realize Si-based optoelectronic devices $^{2-9}$. However, porous Si has one considerable problem with regard to optical stability; the luminescence from porous $\mathrm{Si}$ degrades in ambient air owing to the oxidation of the surface $\mathrm{Si}-\mathrm{H}$ bonds.

There are two effective methods to solve this problem. One is surface termination processing with organic molecules ${ }^{10,11}$. For example, Sato et al. attached acrylic acid to the surface of a Si nanoparticle ${ }^{10}$. This enabled the preparation of stable water-dispersible photoluminescent nanocrystals with yellow or green emission. However, these surface termination methods require one or more complicated wet chemical processes.

Another effective method is to form a thin $\mathrm{SiO}_{2}$ layer on the surface of nanometer-sized $\mathrm{Si}$ via oxidation processes $^{12-15}$. Gelloz et al. prepared porous Si treated by high-pressure water vapor annealing ${ }^{16-20}$. Even though this method achieved a drastic enhancement in the PL efficiency, specialized and expensive equipment was required.

In a recent study, a simple oxidation method to form a high-quality thin $\mathrm{SiO}_{2}$ layer (with a low density of nonradiative recombination centers) on the surface of the porous $\mathrm{Si}$ was proposed ${ }^{21}$. In this method, the PL intensity of the porous Si powder increased when the porous $\mathrm{Si}$ was dispersed in an ethanol solution and aged for several days. However, studies of porous Si aged in organic solvents are limited, and the detail of the oxidation processes and the effect of different types of solvents on the PL properties are not clear at present.

In this study, we confirm the change in the PL intensity of porous $\mathrm{Si}$ via aging in distilled water and organic solvents of ethanol, acetone and hexane. We show that the PL improvements clearly depend on the organic solvents wherein the porous $\mathrm{Si}$ is aged.

\section{EXPERIMENTAL METHOD}

Porous thin films were prepared via standard electrochemical etching of a (100)-oriented, bulk Si substrate with a typical resistivity of $20 \Omega \mathrm{cm}$ in a mixture of hydrofluoric acid and ethanol at a 1:1 ratio. The current density was $30 \mathrm{~mA} / \mathrm{cm}^{2}$. The porous Si thin films were peeled off the Si substrate, milled into fine powder with an agate mortar, and dispersed in distilled water and organic solvents of ethanol, acetone and hexane.

The surface termination (bond structure) of the porous Si was evaluated using FT-IR absorption spectroscopy. Room temperature PL with a wavelength range of $500 \mathrm{~nm}$ - $1000 \mathrm{~nm}$ was measured using a single monochromator equipped with a Peltier-cooled Si CCD sensor. The excitation source used the 405-nm line of a $\mathrm{GaN}$ semiconductor laser.

\section{RESULTS AND DISCUSSION}

Figure 1 shows the FT-IR spectra of porous Si powder aged in organic solvents and distilled water with a wavenumber range of $950 \mathrm{~cm}^{-1}-1350 \mathrm{~cm}^{-1}$. The absorption peak is located at approximately $1080 \mathrm{~cm}^{-1}$ due to the strong absorption of the $\mathrm{Si}-\mathrm{O}$ stretching mode that was observed in all the sample. These absorption peaks, corresponding to the $\mathrm{Si}-\mathrm{O}$ bonds, increased with elapsed time, indicating that surface oxidation of the porous Si occurred in each solvent. However, the amount of oxidation of the porous $\mathrm{Si}$ aged in distilled water was the highest for all the samples. Figures 2(a) - 2(d) show the FT-IR spectra of the porous Si powder aged in organic solvents with a wavenumber range of $1950 \mathrm{~cm}^{-1}-2350$ 
$\mathrm{cm}^{-1}$. We observed an absorption peak at approximately $2100 \mathrm{~cm}^{-1}$ that corresponds stretched vibration mode of the $\mathrm{Si}-\mathrm{H}$ bonds. The absorption peaks of the $\mathrm{Si}-\mathrm{H}$ bonds decreased with elapsed time for all samples. These results indicate that the surface $\mathrm{Si}-\mathrm{H}$ bonds of the porous $\mathrm{Si}$ decreased due to surface oxidation during the aging in the organic solvents.

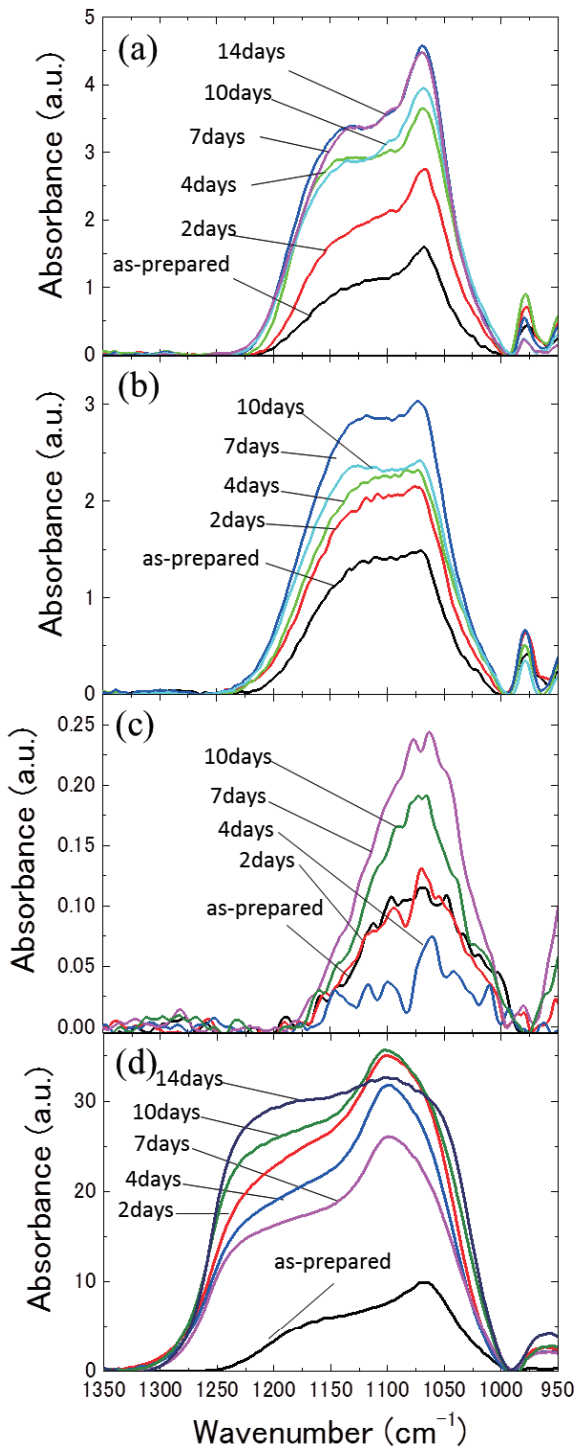

Fig. 1 FT-IR spectra of Porous $\mathrm{Si}$ powder dispersed in (a) ethanol, (b) acetone, (c) hexane and (d) distilled water in wavenumber range of $950 \mathrm{~cm}^{-1}-1350 \mathrm{~cm}^{-1}$.

Figure 3 shows the PL spectra of the porous Si powder aged in (a) ethanol, (b) acetone, (c) hexane and (d) distilled water. Visible and near-infrared luminescence was observed from the porous Si powder dispersed in each solvent. The PL intensity of porous Si in ethanol, acetone, and hexane increased with increasing aging time. However, when porous $\mathrm{Si}$ was dispersed in distilled water, the PL intensity drastically decreased with increasing aging time. Figure 4 shows the PL peak intensity of the porous Si aged in each solvent and distilled water as a function of aging time. The PL peak intensities of the porous $\mathrm{Si}$ were normalized to the intensity of the as-prepared (non-aged) sample. The PL intensity of the porous $\mathrm{Si}$ in the ethanol solution strongly increased up to 50 times in the initial stage of the aging process and then saturated after aging for 4 days. Even though the PL intensities of porous Si aged in acetone and hexane also increased during the 10-day aging process, their increases in PL intensities were lower than that of the ethanol solution. The PL intensity of porous Si experienced up to a 4-fold increase and up to a 10 -fold increase in the acetone and hexane solutions, respectively. In the case of aging in distilled water, the PL peak intensity of the porous Si drastically decreased to $1 / 20$ of the initial PL intensity. Therefore, the oxidation of the porous $\mathrm{Si}$ powder aged in the ethanol solution resulted in the greatest improvement in luminescent intensity.

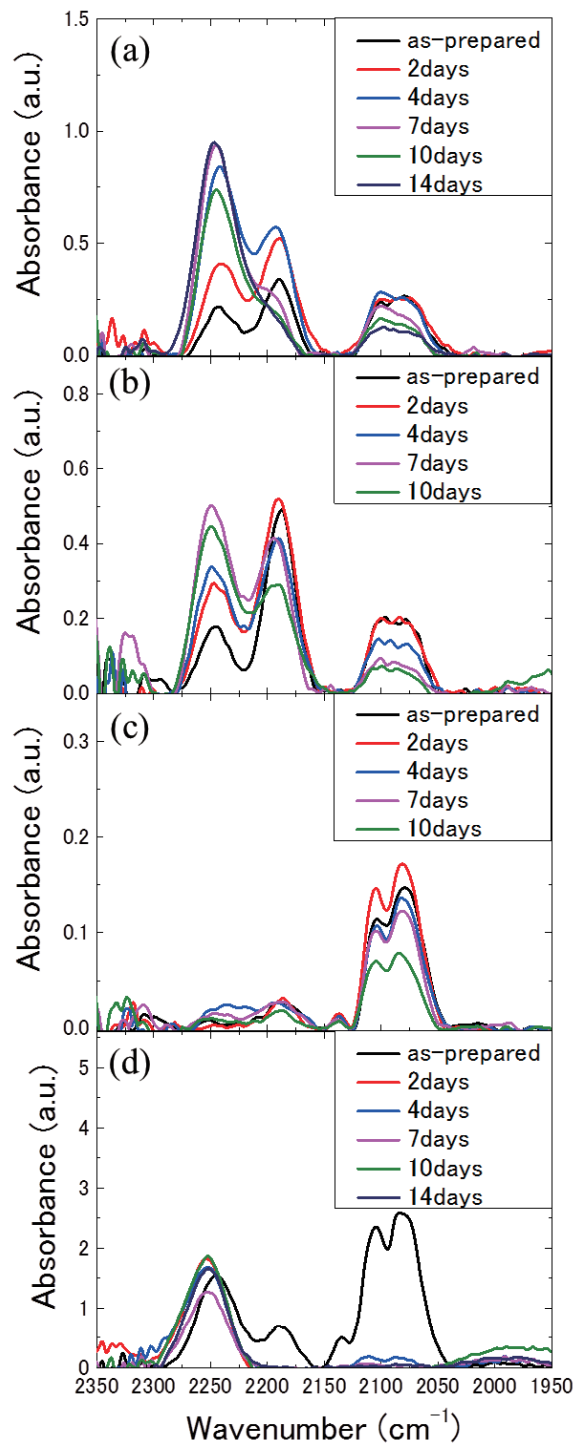

Fig. 2 FT-IR spectra of Porous $\mathrm{Si}$ powder dispersed in (a) ethanol, (b) acetone, (c) hexane and (d) distilled water in a wavenumber range of $1950 \mathrm{~cm}^{-1}-2350 \mathrm{~cm}^{-1}$. 


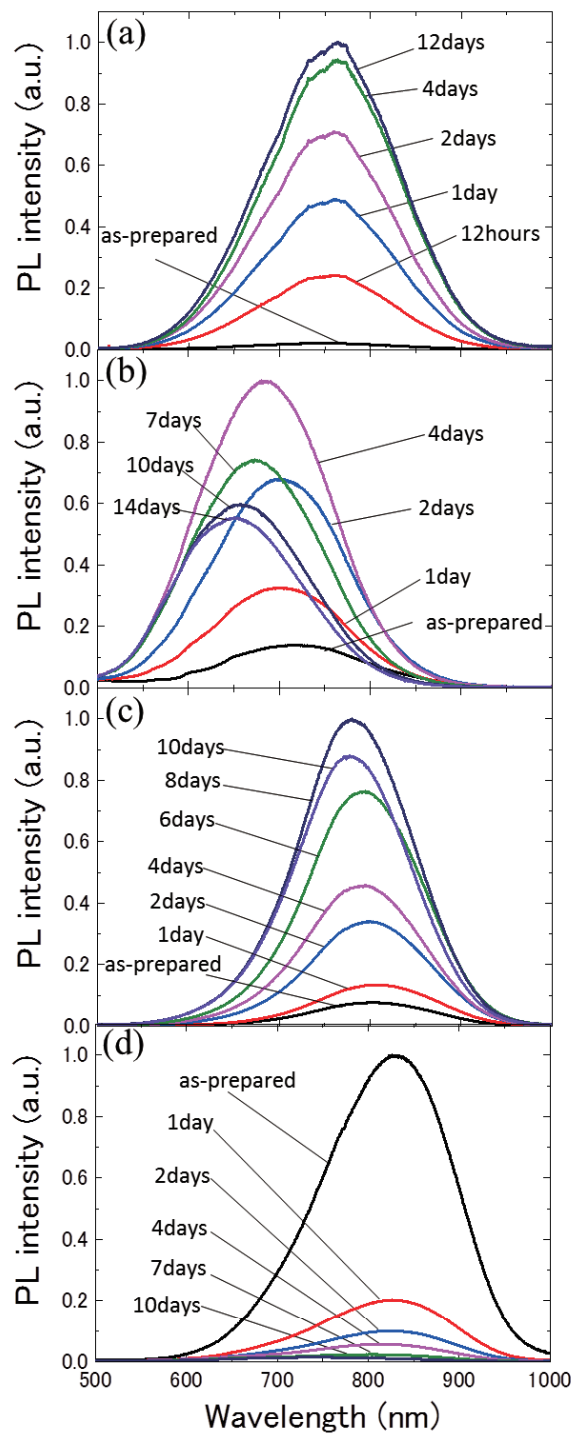

Fig. 3 Change of PL spectra in the milled porous Si powder dispersed in (a) ethanol, (b) acetone, (c) hexane and (d) distilled water with aging time.

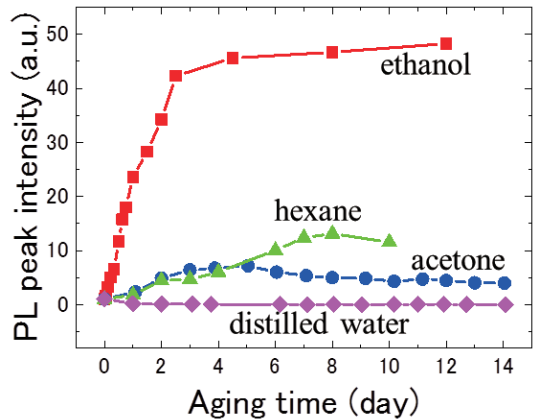

Fig. 4 The PL peak intensity as a function of aging time normalized by the as-prepared sample aged in each solvent and distilled water.

Figure 5 shows the PL peak wavelength of porous $\mathrm{Si}$ as a function of the aging time. The PL peak wavelength of the porous $\mathrm{Si}$ in the ethanol solution did not change during the improvement of the PL intensity. Therefore, the improvement of the PL intensity was caused by the increasing confinement of hole-electron pairs in the porous $\mathrm{Si}$ core via the formation of thin surface oxide films that did not contain nonradiative recombination centers. The PL peak wavelength of the porous Si aged in distilled water shifted to shorter wavelengths as its in PL intensity decreased. This blue shift was likely caused by the formation of a surface oxide layer with nonradiative recombination centers; large porous Si powders are likely to defect formation in the surface oxide due to their larger surface area. Therefore, the decrease in the PL intensity of porous Si aged in distilled water could be explained by the formation of nonradiative recombination centers. Alternatively, the size reduction of the porous Si powder via oxidation could involve a PL blue shift. In fact, the increase in the $\mathrm{Si}-\mathrm{O}$ bond density of the porous $\mathrm{Si}$ dispersed in distilled water during the aging was larger than that of the organic solvents. The increase in the PL intensities of porous $\mathrm{Si}$ aged in acetone and hexane solutions also involved PL blue shifts. These results were likely caused by a combination of the increase in the confinement effect and the formation of nonradiative recombination centers. Therefore, the surface oxidation process of porous $\mathrm{Si}$ aged in acetone or hexane was different from that in the ethanol solution with regard to the formation of nonradiative recombination centers.

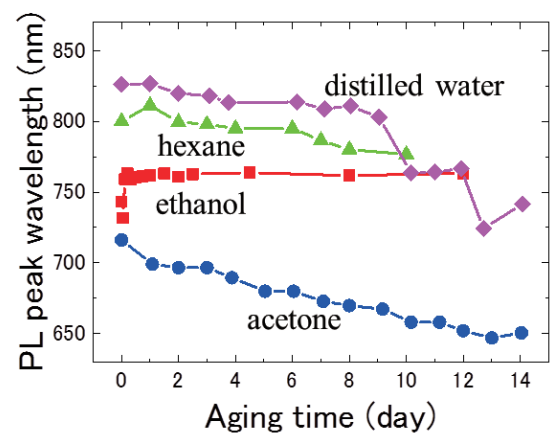

Fig. 5 The PL peak wavelength of the porous $\mathrm{Si}$ aged in each solvent and distilled water as a function of the aging time.

Figure 6 shows the PL peak intensity for porous Si aged in deaerated organic solvents. The PL peak intensity of the porous $\mathrm{Si}$ aged in deaerated ethanol increased slowly in the initial stage of aging. These results indicate that the surface oxidation of the porous $\mathrm{Si}$ was caused by oxygen dissolved in the ethanol, and not components of the solvents. After 4 days of aging in deaerated ethanol, the PL intensity exceeded that of non-deaerated ethanol. The formation of nonradiative recombination centers was suppressed by the slow oxidation. However, the PL intensity of the porous $\mathrm{Si}$ did not change or slightly increased when the porous $\mathrm{Si}$ was aged in deaerated acetone or hexane. These results can be explained as follows. When the porous $\mathrm{Si}$ was aged in deaerated acetone and deaerated hexane, the surface oxidation was suppressed while the formation of nonradiative recombination centers did not change in the deaerated solvents. Therefore, the increase in the PL intensity of the porous $\mathrm{Si}$ aged in the deaerated solvents was smaller than that of porous $\mathrm{Si}$ aged in non-deaerated acetone and hexane. 


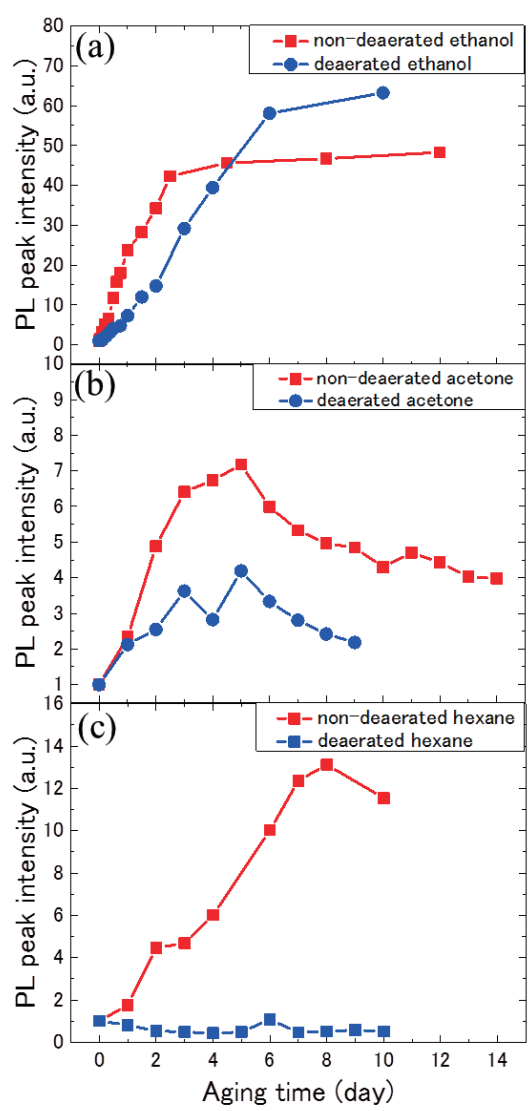

Fig. 6 The PL peak intensity of the porous $\mathrm{Si}$ aged in (a) ethanol, (b) acetone, and (c) hexane for deaerated and non-deaerated solutions.

\section{CONCLUSIONS}

The changes in the PL properties of porous Si aged in ethanol, acetone, hexane and distilled water were investigated. When porous $\mathrm{Si}$ powder was dispersed in ethanol, the PL intensity increased up to 50 times that of the initial intensity during the 4 days of aging. The PL intensity of porous Si powder aged in acetone and hexane increased; however, the increase was smaller than that in the ethanol solution. These increases in the PL intensity in the organic solvents were caused by the surface oxides reacting with dissolved oxygen. However, the PL intensity of porous Si powder aged in distilled water decreased to $1 / 20$ the initial intensity. The PL peak intensity of porous $\mathrm{Si}$ aged in deaerated ethanol increased more than the PL peak intensity of porous $\mathrm{Si}$ aged in non-deaerated ethanol after 4 days. In this study, the PL intensity of porous $\mathrm{Si}$ was improved by aging in several organic solvents, especially ethanol.

\section{REFERENCES}

[1] L. T. Canham, Appl. Phys. Lett. 57, 1046 (1990).

[2] L. Brus, J. Phys. Chem., 98(14), 3575-3581 (1994).

[3] N. M. Park, T. S. Kim and S. J. Park, Appl. Phys. Lett. 78, 17 (2001).

[4] X. Li, Y. He, S. S. Talukdar and M. T. Swihart, Langmuir, 19, 8490-8496 (2003).

[5] K. Y. Cheng, R. Anthony, U. R. Kortshagen and R. J. Holmes, Nano Lett., 10, 1154-1157 (2010).
[6] D. P. Puzzo, E. J. Henderson, M. G. Helander, Z. B. Wang, G. A. Ozin and Z. Lu, Nano Lett., 11, 1585-1590 (2011).

[7] S. Ohta, S. Inasawa and Y. Yamaguchi, Biomaterials, 33, 4639-4645 (2012).

[8] F. Erogbogbo, K. T. Yong, I. Roy, G. X. Xu, P. N. Prasad and M. T. Swihart, ACS Nano, 2, 873-878 (2008).

[9] K. Dohnalova, A. N. Prokofiev, W. D. Boer, C. P. Umesh, J. M. Paulusse, H. Zuilhof and T. Gregorkiewicz, Science \& Application, 2, 47 (2013).

[10] S. Sato and M. Swihart, Chem. Mater, 18, 4083-4088 (2006).

[11] R. Bywalez, H. Karacuban, H. Nienhaus, C. Schulz and H. Wiggers, Nanoscale Res Lett., 7 (2012).

[12] K. A. Littau, P. J. Szajowski, A. J. Muller, A. R. Kortan, L. E. Brus, J. Phys. Chen., 97(6), 1224-1230 (1993).

[13] V. P. Koch, T. Muschik, A. Kux, B. K. Meyer, F. Koch and V. Lehmann, Appl. Phys. Lett., 61, 943 (1992).

[14] A. H. Morshed, M. E. Moussa, S. M. Bedair, R. Leonard, S. X. Liu and N. El-Masry, Appl. Phys. Lett., 70, 1647 (1997).

[15] G. B. Li, L. S. Liao, X. B. Liu, X. Y. Hou and X. Wang, Appl. Phys. Lett., 70, 1284 (1997).

[16] B. Gelloz, A. Kojima and N. Koshida, Appl. Phys. Lett., 87, 031107 (2005).

[17] B. Gelloz, A. Loni, L. Canham and N. Koshida, Nanoscale Res Lett., 7, 382 (2012).

[18] B. Gelloz and N. Koshida, J. Appl. Phys., 98, 123509 (2005).

[19] B. Gelloz and N. Koshida, Jpn. J. Appl. Phys., 46, 2429 (2007).

[20] B. Gelloz, R. Mentek and N. Koshida, Jpn. J. Appl. Phys., 48, 04C119 (2009).

[21] K. Matsumoto, R. Nishio, T. Nomura, K. Kamiya, M. Inada and S. Suzuki, Jpn. J. Appl. Phys., 54, 021301 (2015).

(Received April 30, 2016; Accepted July 11, 2016; Published Online December 1, 2016) 